\title{
HIV Testing and Receiving Test Results by the Female Sex Workers; Retrospective Study using Data from Sri Lanka National HIV Prevention Programme
}

\author{
M. Suchira Suranga, S. Samita, D.A. Karawita
}

\begin{abstract}
Introduction: Improving HIV testing among Key Populations (populations at high risk) is the first step to achieve 90:90:90 treatment targets. Studying the time taken to HIV testing and subsequent clinic visits to uptake the test results provide important inputs for development of HIV prevention programmes.
\end{abstract}

Objectives: This study aims to understand the pattern of HIV testing behavior of Female Sex Workers (FSWs) over the time and provide recommendations for development of HIV prevention programmes for FSWs

Methods: HIV testing data of 5,667 FSWs registered with national HIV prevention programme in 10 Districts of Sri Lanka during 2016 and 2017 were analyzed using, survival data analysis techniques and extended Prentice, Williams \& Peterson (PWP) gap time model.

Results: Time taken to acceptance of HIV test is more dependent on individual factors of FSWs whereas uptake of test result is less dependent on individual factors. Youth FSWs take more time to accept an HIV test. FSWs who are operating in Districts out of Colombo, use condoms, reported undergone HIV testing before join the programme, take more time for HIV testing and uptake test results. FSWs with high partner exchange rate (therefore at high risk) are less likely to complete both events and take more time for testing. Interaction between FSW typology and condom use was found with the use of PWP model.

Conclusion: High risk FSWs are more reluctant for HIV testing and uptake of test results. Factors identified in the study as associated with time taken for both events can be taken into account in planning future HIV preventions programs among FSWs.

Key words: HIV Testing, Female Sex Workers, Test Results, Survival Analysis, Extended PWP Model

Authors: corresponding author; M. Suchira Suranga, B.Sc (Agric.), M.Sc (Bio-Statistics), M.Sc (Management), P.Phil (SRH), Director (Organizational Learning and Evaluation), FPA Sri Lanka, Colombo., (D) https://orcid.org/0000-0002-8200-9572, email:- suchirasuranga@gmail.com

S. Samita, B.Sc (Agric.), M.Phil (Bio-Statistics), PhD (Bio-Statistics), Professor of Bio-Statistics, University of Peradeniya

D.A. Karawita MBBS, PgDVen, MD, FSLCoSHH, Consultant Venereologist, Teaching Hospital, Anuradhapura,

(D) https://orcid.org/0000-0001-9514-9227

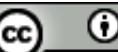

Acknowledgement: Dr. Ariyaratne Manatunga, Ms. Thushara Agus, Mr. Amal Bandara, Mr. Duminda Rajakaruna, Mr. Janaranga Dewasurendra, All the Community Based Organizations, All the STD clinic staff and All the participants in the study, Conflict of interest: Authors claim no conflicts of interest, Funding: not funded, Originality: This is an original work which has been not published anywhere else 


\section{Full Article}

\section{Introduction}

Sri Lanka has been categorized as a country with low-level of HIV epidemic because HIV prevalence has not consistently exceeded $5 \%$ in any of the high risk sub-populations such as female sex workers (FSW), men who have sex with men (MSM), and people who inject drugs (PWID) (1). However, as of end 2017, a cumulative total of 2842 HIV positive cases have been reported to the National STD/AIDS Control Programme (NSACP), Ministry of Health, Sri Lanka. During 2017, total of 285 HIV cases reported to the NSACP and it was the highest number reported in a year (2). In general, an estimate of 10.5 new infections occur per week while, only about 4.5 new cases reported to the NSACP per week.

United nations programme on AIDS (UNAIDS) has set an ambitious target named, 90-90-90 which aims to ensure that $90 \%$ of all people living with HIV will know their HIV status, $90 \%$ of all people diagnosed will receive sustained antiretroviral therapy (ART), and $90 \%$ of all people receiving ART will have viral suppression. (3) Achievement of this treatment target is important for an AIDS free generation in future. Improving HIV testing coverage among key populations (KPs) or most at risk populations is the crucial first step to achieve 90-90-90 treatment targets. Studies indicate that, by 2012, less than 50\% of KPs in many Asian and African countries do not know their HIV status (3). Therefore, it is important that the KP accesses HIV testing periodically to know their HIV status. Turnaround time for non-raid diagnostic tests (non-RDT) is usually few days to weeks. Studies have shown that nearly one third of patients screened for HIV by traditional programs with pre-test information and blood tests that are sent to a central laboratory fail to return for follow-up visits to learn the results (4).

National HIV testing targets cannot be reached without identifying and overcoming the barriers that prevent HIV test uptake by the key populations. Those factors may affect uptake of HIV test and subsequent clinic visits. Moreover, studying the pattern of HIV testing over time and modeling covariates with time taken to uptake HIV testing will provide important inputs for the development of HIV prevention programme.

\section{Objectives}

This study aims to understand the pattern of HIV testing behavior of Female Sex Workers (FSWs) over the time and provide recommendations for development of HIV prevention programmes for FSWs

\section{Method}

Design: cross sectional study using the database maintained at the non-governmental principal recipient of the Global fund for key populations under the national HIV prevention project

Study setting: This study carried out using the database maintained for the national level HIV prevention programme carried out for the key population groups which was funded by the GFATM. The intervention was mainly based on the peer group model where a peer educators are identified, trained and a monthly allowance was paid to provide HIV prevention package (HPP) to about 15 peers under the guidance of field supervisors and district coordinators

This paper examine the data gathered in the female sex worker (FSW) programme. FSW programme was conducted in 10 districts out of 25 districts during 2016-2018 and it included over 200 peer groups covering 5,667 number of peers.

HIV prevention package (HPP) for FSW included six items (9), namely

1 Provision of STI knowledge

2 Provision of HIV knowledge

3 Provision of FSW tailored leaflets

4 Condom-dildo demonstration

5 Provision of condoms

6 Escorting of peers to STD clinic to "take HIV test" and re-escorting to "receive results"

This key population project was mainly handled by the family planning association of 
Sri Lanka (FPASL). Total monitoring and evolution was done by using a web-based monitoring and evaluation information management system (MEIMS) maintained at the FPASL

Study population: The database for the period 01 January 2016 to 31 December 2017 of the National HIV Prevention Programme operated in 10 administrative districts was used for this study which included 5,667 recruited peers (including peer educators). Exclusion criteria: the FSWs who received services less than six months were excluded from the study because it takes approximately 6 months for FSWs to become stable with the project guidelines and services.

Sample size: all the records in the MEIMS were studied retrospectively

Data collection: primary data collection was carried out by using three data collection tools

(I) Client registration form (completed by the peer educator)

(II) STD clinic escort slip or the referral slip (completed by the field supervisor and the STD clinic doctor)

(III) Results slip (completed by the field supervisor and the STD clinic doctor)

The potential duplication and false claims were prevented by making a unique identification code (UIC) for each peer at the time of client registration. These data entered monthly by contracted organizations through the webportal to the monitoring and evaluation information management system (MEIMS). Escort verification was done by the central level through escort slips and result slips signed by the relevant district STD clinic doctor which need to be sent each month by post or by currier system from the STD clinic. Data available in the web-based MEIMS maintained at the FPASL is the main data source for this study (5).

Period of data taken for the analysis: The database for the period 01 January 2016 to 31 December 2017 of the National HIV Prevention Programme operated in 10 Administrative Districts was used for this study.
Data Analysis: As the focus of the study was "time to take HIV test" and "time to receive results" by FSWs. Time to event was analyzed using survival analysis methods.

The Kaplan-Meier (KM) estimator was used to estimate the survival function from lifetime data. (6) This study used the log rank test to compare the survival curves.

Multivariate survival analysis with extended Prentice, Williams \& Peterson (Extended PWP) model, was used. (7)

Two events, considered in this study were (i) time to take HIV test, and (ii) time to receive results. The two events are serial events and thus time to an event can be considered in two ways as, total time (TT) and gap time (GT). Out of the two choices, PWP model for GT is considered to be better to describe the HIV testing behavior of KPs (8), and therefore we used PWP GT model in the study. In fitting PWP GT model in the study, two gap times considered were, time to take-up the test $\left(T_{1}\right)$ and time from take-up to receive the test results $\left(T_{2}\right)$. Therefore, two survival times for the PWP GT model are $T_{1}$ and $T_{2}$. The hazard function model for $j^{\text {th }}$ event of the $i^{\text {th }}$ subject is given by (9).

$$
\lambda_{i j}(t)=\lambda_{0 j}\left(t-t_{j-1}\right) \exp \left(\mathbf{x}_{i}^{\prime} \boldsymbol{\beta}\right)
$$

where;

$\mathbf{x}_{\mathrm{i}} \quad=$ Covariate vector for subject $i$

$\boldsymbol{\beta}=$ Vector of coefficients

$\lambda_{0 j}=$ event-specific baseline hazard for the $j^{\text {th }}$ event $(j=1,2)$

The statistical software IBM SPSS 20 was used for preliminary survival analysis, KM estimation and hypothesis testing. The SAS University edition was used for multivariate survival analysis.

Ethical Considerations: ethics review committee (ERC) of the Sri Lanka Medical Association (SLMA) granted clearance on 20th April 2018 (ERC-18-007). ERC exempted detailed review as the study is based on secondary data and there is no direct involvement of human participants. 
Organizational permission was taken from the executive director of the FPASL

\section{Results}

\section{Sample Characteristics}

After data cleaning and checking for exclusion criteria, 5667 FSWs were included in the study. Out of them $44.7 \%$ were from the Colombo District and $18.1 \%$ were from the Gampaha
District. Rest of the FSWs were from Kandy (9\%), Galle (6.6\%), Ratnapura (5.3\%), Polonnaruwa(4.5), Matara (4.2\%), Kurunegala (3.3\%), Anuradhapura (2.8\%) and Hambantota (1.5\%) Districts. The geographical distribution of the sample was aligned with the estimated percentage of FSWs in each District of Sri Lanka (10). Table 1 presents the composition of the sample in detail.

Table 1:- Sample characteristics

\begin{tabular}{|c|c|c|c|c|}
\hline Variable & Levels & Count & Percent & Cumu. Percent \\
\hline \multirow[t]{3}{*}{ Age } & Below 25 & 382 & 6.8 & 6.8 \\
\hline & 25 and Above & 5269 & 93.2 & 100.0 \\
\hline & Total & 5651 & 100.0 & \\
\hline \multirow[t]{3}{*}{ Level of Education } & Up to Gr. 09 & 3083 & 54.4 & 54.4 \\
\hline & 10 and above & 2584 & 45.6 & 100.0 \\
\hline & Total & 5667 & 100.0 & \\
\hline \multirow[t]{7}{*}{ Marital Status } & Never married & 398 & 7.1 & 7.1 \\
\hline & Married & 3610 & 64.8 & 71.9 \\
\hline & Living together & 436 & 7.8 & 79.7 \\
\hline & Separated & 206 & 3.7 & 83.4 \\
\hline & Divorced & 405 & 7.3 & 90.7 \\
\hline & Widow & 520 & 9.3 & 100.0 \\
\hline & Total & 5575 & 100.0 & \\
\hline \multirow{5}{*}{$\begin{array}{l}\text { FSW typology } \\
\text { (based in) }\end{array}$} & Streets/slums & 3291 & 59.9 & 59.9 \\
\hline & Lodge/Hotels /Brothels etc. & 604 & 11.0 & 70.9 \\
\hline & Massage Centre & 1145 & 20.8 & 91.7 \\
\hline & Other & 456 & 8.3 & 100.0 \\
\hline & Total & 5496 & 100.0 & \\
\hline \multirow{3}{*}{$\begin{array}{l}\text { Number } \\
\text { Partners }\end{array}$} & 20 or less & 4212 & 74.7 & 74.7 \\
\hline & $>20$ & 1425 & 25.3 & 100.0 \\
\hline & Total & 5637 & 100.0 & \\
\hline \multirow{3}{*}{$\begin{array}{l}\text { HIV test done } 1 \text { year } \\
\text { before joining }\end{array}$} & Yes & 3172 & 56.6 & 56.6 \\
\hline & No & 2428 & 43.4 & 100.0 \\
\hline & Total & 5600 & 100 & \\
\hline \multirow[t]{3}{*}{ Condom use at last sex } & Yes & 4244 & 24.4 & 24.4 \\
\hline & No & 1372 & 75.6 & 100.0 \\
\hline & Total & 5616 & 100.0 & \\
\hline
\end{tabular}

\section{Kaplan-Meier estimation and hypothesis testing}

Kaplan-Meier analysis was performed for $T_{1}$ and $T_{2}$ separately to estimate median escort time with $95 \%$ confidence interval. The log rank test was performed to compare the survival curves of different levels of each factor.

The estimated median time for HIV testing and subsequent clinic visits along with the results of log rank test is presented in Table 2. 
Table 2:- Results of median survival estimates and comparison between levels of each factor

\begin{tabular}{|c|c|c|c|c|c|}
\hline \multirow[b]{2}{*}{ Variables } & \multirow[b]{2}{*}{ Levels } & \multicolumn{2}{|c|}{$\begin{array}{l}\text { Time taken to HIV testing from } \\
\text { registration (first event) }\end{array}$} & \multicolumn{2}{|c|}{$\begin{array}{r}\text { Time taken to receive test } \\
\text { results from HIV testing } \\
\text { (Second event) }\end{array}$} \\
\hline & & $\begin{array}{r}\text { Median } \\
\text { Survival } \\
\text { Time in \# of } \\
\text { days }\end{array}$ & $\begin{array}{r}\text { Log Rank Test } \\
\text { Statistic } \\
\text { (Significance) }\end{array}$ & $\begin{array}{r}\text { Median } \\
\text { Survival } \\
\text { Time in \# } \\
\text { of days }\end{array}$ & $\begin{array}{r}\text { Log Rank Test } \\
\text { Statistic } \\
\text { (Significance) }\end{array}$ \\
\hline \multirow[b]{2}{*}{ Age } & 24 and below & 419 & $0.03(P=0.857)$ & 36 & $6.41(P=0.011)$ \\
\hline & Above 25 & 514 & & 23 & \\
\hline \multirow[t]{2}{*}{ Marital Status } & Never married & 514 & $0.01(P=0.913)$ & 29 & $6.36(P=0.012)$ \\
\hline & Ever married & 507 & & 22 & \\
\hline \multirow[t]{2}{*}{ Level of Education } & Up to grade 09 & 567 & $39.85(P=0.000)^{*}$ & 24 & $0.03(P=0.863)$ \\
\hline & $\begin{array}{l}\text { Grade } 10 \text { and } \\
\text { above }\end{array}$ & 448 & & 24 & \\
\hline \multirow[t]{3}{*}{ Location } & Rural & 640 & $3.98(P=0.056)$ & 17 & $10.49(P=0.005)$ \\
\hline & Peri urban & 580 & & 35 & \\
\hline & Urban & 477 & & 22 & \\
\hline \multirow[t]{5}{*}{ FSW Typology } & Based in street & & $64.05(P=0.000)^{*}$ & 24 & $15.24(P=0.000)$ \\
\hline & $\begin{array}{l}\text { own houses or } \\
\text { slums }\end{array}$ & 569 & & & \\
\hline & Based in Lodge / & & & 37 & \\
\hline & $\begin{array}{l}\text { Hotels / Brothels } \\
\text { or Restaurants }\end{array}$ & 530 & & & \\
\hline & $\begin{array}{l}\text { Based in } \\
\text { Massage Centre }\end{array}$ & 369 & & 22 & \\
\hline \multirow{2}{*}{$\begin{array}{l}\text { Duration of Selling } \\
\text { Sex }\end{array}$} & Up to 5 years & 476 & $3.98(P=0.056)$ & 24 & $0.00(P=0.987)$ \\
\hline & $>5$ years & 530 & & 23 & \\
\hline \multirow{2}{*}{$\begin{array}{l}\text { Number of sexual } \\
\text { partners during the } \\
\text { last month }\end{array}$} & Up to 20 & 477 & $17.20(P=0.000)^{*}$ & 22 & $12.50(\mathrm{P}=0.000)^{*}$ \\
\hline & $>20$ & 547 & & 33 & \\
\hline \multirow{2}{*}{$\begin{array}{l}\text { Used a condom in } \\
\text { last sex }\end{array}$} & No & 431 & $54.04(P=0.000)^{*}$ & 18 & $17.08(\mathrm{P}=0.000)$ \\
\hline & Yes & 533 & & 27 & \\
\hline \multirow{2}{*}{$\begin{array}{l}\text { Subjected for a HIV } \\
\text { test during the past } \\
12 \text { months }\end{array}$} & No & 443 & $98.22(P=0.000)^{*}$ & 21 & $13.90(\mathrm{P}=0.000)$ \\
\hline & Yes & 593 & & 29 & \\
\hline \multirow{2}{*}{$\begin{array}{l}\text { Subjected for a STI } \\
\text { test during the past } \\
12 \text { months }\end{array}$} & No & 442 & $105.31(P=0.00)^{*}$ & 21 & $18.67(P=0.000)^{*}$ \\
\hline & Yes & 596 & & 31 & \\
\hline \multirow{2}{*}{$\begin{array}{l}\text { Ever being treated } \\
\text { for STI }\end{array}$} & No & 487 & $4.75(P=0.029)^{*}$ & 24 & $1.32(P=0.250)$ \\
\hline & Yes & 549 & & 27 & \\
\hline
\end{tabular}

* Statistically Significant at $\alpha=0.05$ level

Table 2 describes the pattern of HIV testing and uptake of HIV test results by the FSWs during 2016 and 2017. The median survival time is the time at which $50 \%$ of the FSWs have reached the desired event. According to the results, median of $T_{1}$ of the FSWs of younger age group was 419 days whereas the median of $T_{2}$ for this group was 36 days. For the older age group, the median of $T_{1}$ was 514 days where as median of $T_{2}$ was 23 days. However, the log-rank test indicated that there is no median difference between two age groups with respect to $T_{1}(P=0.857)$ but there is a difference in median with respect to $T_{2}(P=$ 0.011), where older age group FSWs have taken significantly less median time compared to that of younger age group to uptake the test result. 
Similarly, FSWs, with higher educational level (grade 10 and above) as compared to with lower educational level, based in massage centres as compared to base in other places, with lower duration of selling sex (less than 5 years) as compared to with longer duration of selling sex, with low partner exchange rate (less than 20 per month) as compared to with high partner exchange rate, who have not used condoms during the last sex as compared to those who have used condoms, who have not subjected to HIV or STI test during past 12 months as compared to who have subjected to HIV or STI test, and who have not been treated for STIs during their life time as compared to who have been treated during their life time are likely to uptake HIV test in a significantly shorter period of time.

Figure 1:- Graphical presentation of time dependency of "condom use" for different types of FSWs.. Hazard Ratio for "not using condoms" for different FSW types is presented over time.. FSWs who "use condoms" were considered as the

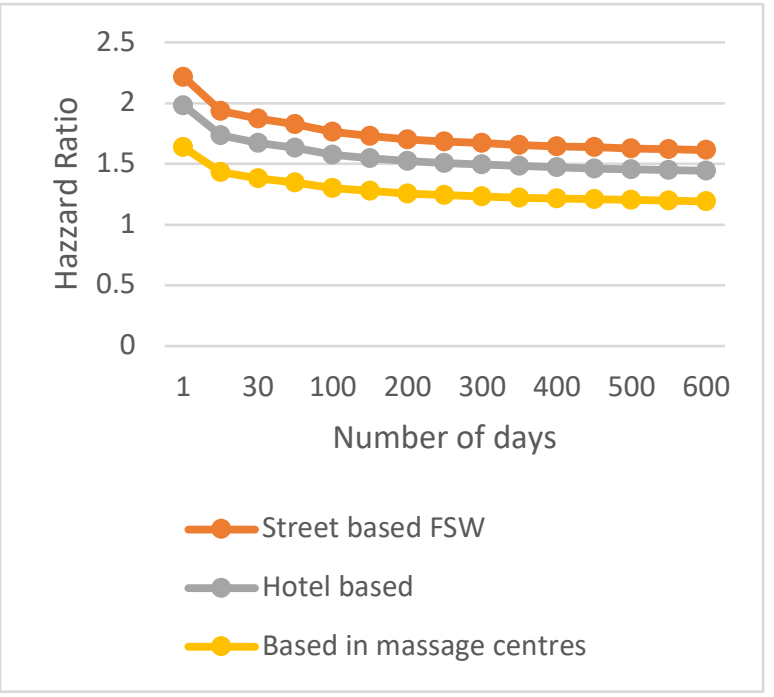

\section{Results of the Extended Prentice, Williams \& Peterson (EPWP) Gap Time Model}

Results show that $47 \%$ of FSWs have tested for HIV during the period of two years. Out of the FSWs who have tested for HIV, only $68 \%$ have revisited STD clinics to obtain the test result. The general PWP GT model was initially performed using SAS PHREG procedure for completion of two events simultaneously. The resulted model then assessed for proportional hazard assumption. After observing the residual plots, it was suspected that that hazards are not proportional for some of the covariates as clear pattern was observed in residuals. The distance between lines was not constant in "log-negative-log" plots for some of the covariates suggesting non-proportional hazard. The proportionality test of SAS procedure confirmed that overall model violated proportional hazard assumption.

Therefore interaction terms between time and all the covariates were included in the model for the predictors (covariates) with nonproportional hazard. As explained in the methodology, the resulted model which includes time dependent covariates is called extended PWP model. Comparing initial models (general PWP model) and final models (extended PWP model), it was observed that information criteria have lower values in final models indicating better fit. The "log(time)" was used instead of "time" itself as the models with $\log$ (time) showed a better fit. The estimated hazard ratios for the levels of variables from the EPWP gap time model, which included time dependent covariates are summarized in table 3.

Results of extended PWP Gap Time model was fully consistent with median survival time of KM estimates. Table 3 Age, number of sexual partners during the last month reported at the time of registration, testing for HIV before join with the project, District, education category, reported using condoms during the last sex at the time of registration, typology and interaction effect between typology and condom use were significant and retained in the model. Typology, condom use and number of sexual partners were identified as time dependent covariates. Hazard ratio is interpreted as hazard of a particular level relative to hazard of the reference level. If the event is completed in shorter period of time, then hazard is said to higher. In this study the end point is beneficial / desired and thus high hazard ratio implies that time taken to take up the test (T1) and time taken to receive the results (T2) in general is less. FSWs who reported not using condoms are more likely to complete both events within a shorter period of time. 
Table 3:- Estimated hazard ratios, and confidence interval from EPWP GT Model

\begin{tabular}{|c|c|c|c|}
\hline Variable & Level & $\begin{array}{l}\text { Hazard Ratio } \\
(95 \% \mathrm{Cl})\end{array}$ & P Value \\
\hline Age (age in years) & & $1.005(1.002-1.009)$ & 0.004 \\
\hline District (1=Colombo 2=Others) & 2 & $0.877(0.820-0.93)$ & $<0.001$ \\
\hline Number of Sexual Partners & & $0.984(0.978-0.989)$ & $<0.001$ \\
\hline $\begin{array}{l}\text { HIV testing ( } 1=\text { Not subjected for an HIV test } \\
\text { during past year } 2=S u b j e c t e d \text { for an HIV test } \\
\text { during past year) }\end{array}$ & 2 & $0.810(0.754-0.871)$ & $<0.001$ \\
\hline $\begin{array}{l}\text { Condom Use (1=Not used condoms during the } \\
\text { last sexual encounter } 2=\text { Used condoms during } \\
\text { the last sexual encounter) }\end{array}$ & 2 & $0.451(0.366-0.555)$ & $<0.001$ \\
\hline $\begin{array}{l}\text { Education Category (1=up to grade eight 2=grade } \\
\text { nine and above 2) }\end{array}$ & 2 & $1.116(1.041-1.195)$ & 0.002 \\
\hline Typology (1=Based in street own house or slums & 2 & $0.979(0.756-1.269)$ & 0.8738 \\
\hline $\begin{array}{l}2=\text { Based in hotels lodges brothels or restaurants } \\
3=\text { Based in Massage Centers) }\end{array}$ & 3 & $1.153(0.940-1.415)$ & 0.1726 \\
\hline \multicolumn{4}{|l|}{ Interaction Effect } \\
\hline \multirow[t]{2}{*}{ Condom use*typology } & $2 / 2$ & $1.118(0.853-1.466)$ & 0.419 \\
\hline & $2 / 3$ & $1.355(1.145-1.604)$ & $<0.001$ \\
\hline \multicolumn{4}{|c|}{ Contrasts (Condom use after controlled for typology) } \\
\hline Condom use 1 vs 2 at typology $=1$ & & $2.217(1.801-2.729)$ & $<0.001$ \\
\hline Condom use 1 vs 2 at typology $=2$ & & $1.983(1.454-2.703)$ & $<0.001$ \\
\hline Condom use 1 vs 2 at typology $=3$ & & $1.636(1.332-2.010)$ & $<0.001$ \\
\hline \multicolumn{4}{|l|}{ Contrasts (Typology after controlled for condom use) } \\
\hline Typology 1 vs 2 at condom use $=1$ & & $1.021(0.788-1.323)$ & 0.231 \\
\hline Typology 1 vs 3 at condom use $=1$ & & $0.867(0.706-1.064)$ & 0.087 \\
\hline Typology 2 vs 3 at condom use $=1$ & & $0.849(0.651-1.108)$ & 0.137 \\
\hline Typology 1 vs 2 at condom use $=2$ & & $0.913(0.784-1.063)$ & 0.145 \\
\hline Typology 1 vs 3 at condom use $=2$ & & $0.640(0.520-0.787)$ & $<0.001$ \\
\hline Typology 2 vs 3 at condom use $=2$ & & $0.701(0.599-0.820)$ & 0.701 \\
\hline \multicolumn{4}{|l|}{ Time Dependent Covariates } \\
\hline Typology*log(Time) & & $0.968(0.945-0.991)$ & 0.006 \\
\hline Condom Use*log(Time) & & $1.159(1.104-1.216)$ & $<0.001$ \\
\hline Sexual Partners*log(Time) & & $1.004(1.002-1.005)$ & $<0.001$ \\
\hline
\end{tabular}

However, the effect of condom use on HIV testing behavior is depended on the typology of FSW. Highest difference between condom users and non-users can be observed among street based sex workers (121\%), followed by hotel based sex workers (98\%) and sex workers based in massage centers (63\%). Effect of condom use on HIV testing shows a declining trend over the time. Street based sex workers who are using condoms are $36 \%$ less likely to complete both events compared to the massage center sex workers who are using condoms. Same phenomena can be observed among hotel based FSWs compared to massage-center based FSWs.

According to table 03, the number of sexual partners during the last month at the time of registration shows a negative association with $T_{1}$ and $T_{2}$ when the two events are considered together. Increase in number of sexual partners by one partners decrease the chance of completing the events by $2 \%$. However, this effect shows a declining trend over time and almost disappear $(0.1 \%)$ by end of first 600 days. Odds of completing both events is $12 \%$ 
higher for educated FSWs compared to their uneducated counterparts. Increase in age by 10 years will increase the chance of completing both events by $5 \%$. FSWs who had tested for HIV during past 12 months before joining with the programme shows $19 \%$ lower chance of completing both events.

\section{Discussion}

Sri Lanka national HIV testing guidelines (11) clearly highlight that KPs including FSWs must test for HIV once in a six month (at least annual testing is promoted based on partner exchange rate and practice of safe sex). However, findings of this study shows that testing for HIV within 12 months before joining the programme significantly reduce (by $19 \%$ ) undergoing uptake of HIV test as well as receiving test results. This effect is significant even after two years. This effect is assumed to be much higher among the FSWs who are not covered (or reached) by the prevention interventions. This indicate the gap between the national target in terms of testing frequency of KPs and actual testing behavior. Future interventions must focus on increasing HIV testing frequency of Female Sex Workers.

Findings of this study shows that acceptance of HIV test is more dependent on individual factors of FSWs whereas uptake of test result is less dependent on individual factors. The subsequent clinic visit to uptake the test result may more depend on the facility and service provider related factors such as personal experience of the first visit, effectiveness of pretest counselling, stigma and discrimination, waiting time, etc. It is clear that the time taken to uptake test results cannot be reduced without improving these Quality of Care Standards.

It is evident that the HIV testing behavior of the FSWs based in Colombo District is significantly different from FSWs based in other Districts, after controlled for all socio demographic and behavioral factors. FSWs based out of Colombo District shows $13 \%$ lower chance of testing for HIV and receiving test results compared to the FSWs based in Colombo District in a given point of time. The chance of loss to follow-up after the first clinic visit is also higher for the FSWs who are based out of Colombo. It is important to highlight the fact that the condom use is also lower among the FSWs based in out of Colombo Districts (68\%) compared to Colombo District (85\%). This may be due to early start of HIV prevention programmes in Colombo District compared to peripheral Districts. Currently a uniform prevention model is applied across the island (20). The results of this study highlight the requirement for development of different prevention strategies for out of Colombo District FSWs.

Time taken to HIV testing and uptake test results is clearly dependent on the FSWs typology. Street Based SWs and Hotel Based SWs are less likely to complete both events compared to the SWs based in massage centers after controlled for all socio demographic and behavioral factors. The current HIV prevention programme implement a uniform prevention model among all types of FSWs $(21 ; 20)$. Findings of this study clearly shows the requirement for development and implementation of focus interventions considering the FSW typology.

Formal education is one of the underline factor for most of community health issues. It is clear that the FSWs who are educated up to grade 09 or more are more likely to test for HIV and receive the test results after controlling for all other sociodemographic and behavioral factors. This effect is significant even after two years of HIV prevention interventions. The educated FSWs represent around $46 \%$ of the selected FSW cohort. Special attention must be given for less-educated sub population of FSWs when selecting for the interventions and implementing the programme. Level of education needs to be considered as one of the important criteria in selection and programme design. Some of the current interventions such as distribution of leaflets, IEC/BCC materials may not be useful for less educated FSWs (5).

Results clearly highlight that the FSWs who are using condoms are less likely to complete both events than the FSWs who are not using condoms. FSWs who are using condoms take relatively longer time to test for HIV and uptake the test result. This difference HIV 
testing behavior among condom users and non-users is highest among street based SWs followed by hotel based SWs and the SWs based in massage centers. This effect of condom use on HIV testing is significant event after implementation of HIV prevention interventions for two years. This may be due to the perceived low risk among the FSWs who use condoms. The prevention programmes should clearly communicated to its clients (the FSWs) the fact that the testing for HIV at least once in a year is important even they are using condoms consistently as "using condoms" also not $100 \%$ protective.

Number of sexual partner (partner exchange rate) is one of the most important risk factors for HIV and other Sexually Transmitted Infections (STI). The findings of this study clearly conclude that the FSWs who are having higher partner exchange rate (therefore more risky) are less likely to test for HIV and take longer time for HIV testing. The chance of loss to follow-up after the first clinic visit is also higher among this high risk FSWs. So, it is clear that the HIV infected FSWs with high number of clients are operated in the field for longer time without knowing their HIV status (therefor without taking treatments) and infect for higher number of clients. However, one good aspect to highlight is that the FSWs with high partner exchange rate (above 20) are more likely to use condoms (90\%) than FSWs with less partner exchange rate (71\%). It is important to identify high risk FSWs at the time of registration and must provide a specific and more targeted prevention service package to the high risk FSWs.

\section{Conclusion}

The Street Based Female Sext workers operating out of Colombo District, who reported high number of sexual partners, testing for HIV before joining the programme, use condom during the last sexual intercourse, less formal education are likely to take longer time to complete HIV testing and uptake the test result. The effect of these factors is declining over time however significant even after two years of HIV prevention intervention. More focus and tailor-made interventions are needed to increase the HIV testing among different sub -populations of FSWs.

\section{References}

1. UNAIDS/WHO. Guidelines for second generation HIV surveillance. World Health Organization. Geneva : s.n., 2000.

2. NSACP. Annual Report - 2017. Colombo, Sri Lanka : National STD / AIDS Control Programme, Ministry of Health, Sri Lanka, 2018.

3. UNAIDS. 90-90-90; An ambitious treatment target to help end the AIDS epidemic . 1st. Geneva : Joint United Nations Programme on HIV/AIDS, 2014.

4. A rapid review of rapid HIV antibody tests. Greenwald, L J, et al. 2, 2006, Current Infectious Disease Reports, Vol. 8, pp. 125-31.

5. NSACP. Sri Lanka National HIV Monitoring and Evaluation Plan (2016-2022). Colombo: National STD/AIDS Control Programme, 2017.

6. Nonparametric estimation from incomplete observations. Kaplan, L E and Meier, P. [ed.] John Tukey. 282, 1958, Journal of the American Statistical Association, Vol. 53, pp. 457-481.

7. Regression Analysis of Multivariate Failure Time Data. Prentice, R L, Williams, B J and Peterson, A V. 1981, Biometrika, Vol. 68, pp. 373-379.

8. 8. Suranga, M S. Modeling Time Taken to HIV Testing and Follow-up Clinic Visits to Collect the Test Results; Multivariate Survival Analysis. Peradeniya: Thisis submitted for Master of Science in Bio-statistics, University of Peradeniya, 2019.

9. Analysis of Survival Data with Recurrent Events Using SAS. Sun, Rena Jie and Cotton, Daniel . 2010, SAS Global Forum - 2010, p. Paper 255.

10. 10. NSACP. National size estimation of most-at-risk populations (MARPs) for HIV in Sri Lanka. National STD/AIDS Control Programme, Ministry of Health. Colombo: National STD/AIDS Control Programme, 2018.

11. NSACP. National HIV Testing Guideline - Sri Lanka. Colombo: National STD and AIDS Control Programme, 2016.

12. NSACP . Sri Lanka National HIV Prevention Strategic Plan; 2018-2022. Colombo: National STD/AIDS Control Programme, 2017.

13. 13. NSACP. National HIV Strategic Plan; 2013-2017. Colombo: National STD/AIDS Control Programme, 2013.

14. AIDSinfo. U.S. Department of Health and Human Services. [Online] 2016. [Cited: February 09, 2018.] https://aidsinfo.nih.gov/understanding-hivaids/fact-sheets/19/47/hiv-testing.

15. NSACP. Annual Report 2015. National STD/AIDS Control Programme, Ministry of Health. Colombo: s.n., 2016.

16. NSACP. Integrated Biological and Bahavioural Surveillance Survey Among Key Population at Higher Risk of HIV in Sri Lanka. Colombo : Nationa STD / AIDS Control Programme, 2015. pp. 12-14. 978-955-050571-5.

17. Alliance South Asian Regional Technical Hub. Procedure Mannual for Implementtion of GFATM 
round-09 HIV Prevention Programme. Colombo : The Family Planning Association of Sri Lanka, 2013.

18. NSACP. Mid Term Review, 2013-2017 National Strategic Plan. Colombo : National STD / AIDS Control Programme, 2015.

19. NSACP. External Review Report; National Health Sector Response to HIV and Sexually Transmitted Infections in Sri Lanka. Colombo : National STD/AIDS Control Programme, 2017.

20. The Family Planning Association of Sri Lanka. Monitoring and Evaluation Policy. Colombo: s.n., 2013.

21. Appraisal of Several Methods to Model Time to Multiple Events per Subject: Modelling Time to Hospitalizations and Death. Castañedaa, Javier and Gerritse, Bart . 1, 2010, Revista Colombiana de Estadística, Vol. 33, pp. 43-61.

22. Modeling time taken for HIV testing and visits in follow-up clinic to uptake test results: an application of extended Cox proportional hazard model. Mullege, Suchira Suranga and Samita, S. 2020/3, Colombo, Sri Lanka: Official journal of the Polish AIDS Research Society (PTN AIDS), 2020, HIV \& AIDS Review. International Journal of HIV-Related Problems, Vol. 19, pp. 157-166. 1732-2707. 